\title{
BMJ Open Carpal tunnel syndrome and computer exposure at work in two large complementary cohorts
}

\author{
Z Mediouni, ${ }^{1,2,3}$ J Bodin, ${ }^{4}$ A M Dale, ${ }^{5}$ E Herquelot, ${ }^{1,2}$ M Carton, ${ }^{1,2}$ A Leclerc, ${ }^{1,2,6}$ \\ N Fouquet, ${ }^{4,7}$ C Dumontier, ${ }^{8}$ Y Roquelaure, ${ }^{4,9}$ B A Evanoff, ${ }^{5}$ A Descatha ${ }^{6,1,2,3}$
}

To cite: Mediouni Z, Bodin J, Dale AM, et al. Carpal tunnel syndrome and computer exposure at work in two large complementary cohorts. BMJ Open 2015;5:e008156. doi:10.1136/bmjopen-2015008156

- Prepublication history for this paper is available online. To view these files please visit the journal online (http://dx.doi.org/10.1136/ bmjopen-2015-008156).

Received 10 March 2015 Revised 14 August 2015 Accepted 21 August 2015

CrossMark

For numbered affiliations see end of article.

Correspondence to Professor A Descatha; alexis.descatha@inserm.fr

\section{ABSTRACT}

Objectives: The boom in computer use and concurrent high rates in musculoskeletal complaints and carpal tunnel syndrome (CTS) among users have led to a controversy about a possible link. Most studies have used cross-sectional designs and shown no association. The present study used longitudinal data from two large complementary cohorts to evaluate a possible relationship between CTS and the performance of computer work.

Settings and participants: The Cosali cohort is a representative sample of a French working population that evaluated CTS using standardised clinical examinations and assessed self-reported computer use. The PrediCTS cohort study enrolled newly hired clerical, service and construction workers in several industries in the USA, evaluated CTS using symptoms and nerve conduction studies (NCS), and estimated exposures to computer work using a job exposure matrix.

Primary and secondary outcome measures: During a follow-up of 3-5 years, the association between new cases of CTS and computer work was calculated using logistic regression models adjusting for sex, age, obesity and relevant associated disorders.

Results: In the Cosali study, 1551 workers (41.8\%) completed follow-up physical examinations; $36(2.3 \%)$ participants were diagnosed with CTS. In the PrediCTS study, 711 workers $(64.2 \%)$ completed follow-up evaluations, whereas $31(4.3 \%)$ had new cases of CTS. The adjusted $\mathrm{OR}$ for the group with the highest exposure to computer use was $0.39(0.17 ; 0.89)$ in the Cosali cohort and $0.16(0.05 ; 0.59)$ in the PrediCTS cohort.

Conclusions: Data from two large cohorts in two different countries showed no association between computer work and new cases of CTS among workers in diverse jobs with varying job exposures. CTS is far more common among workers in non-computer related jobs; prevention efforts and work-related compensation programmes should focus on workers performing forceful hand exertion.

Carpal tunnel syndrome (CTS) is a common, painful and costly disease among working adults. It is also the most common entrapment neuropathy of the upper limb. ${ }^{12}$ Studies on CTS have reviewed the potential

\section{Strengths and limitations of this study}

- The study had limitations: attrition for the Cosali cohort and definition based on clinical examination, representativeness of the PredicTS study, measures used to assess the exposure to computer use.

- The strengths of both cohorts were their prospective, longitudinal study design and the rigorous case definitions of incident CTS cases.

- The Cosali cohort was representative of a French region's working population, and the PredicTS study followed a large group of workers over a long period of time with low attrition and used a robust case definition that included nerve conduction studies.

- The similar association values found in the two studies is noteworthy.

risk factors and confirmed its relationship with biomechanical exposure at work ${ }^{3-6}$ CTS occurs more frequently among workers in occupations with high physical exposures, that is, forceful and repetitive hand movements combined with awkward posture..$^{56}$

However, the growing use of computers and the concurrent increase in musculoskeletal complaints among users have led to a longrunning controversy over the role that exposure to computer use may play in the development of CTS. Some past studies have shown a possible link between computer exposure at work and musculoskeletal disorders including CTS. $^{7} 8$ Recently, published studies have shown opposite results, ${ }^{5}{ }^{9-11}$ and several reviews concluded that there was no evidence for such an association. ${ }^{5}{ }^{12-15}$ Only one study has used a longitudinal design, and found a positive association between right-handed mouse use (over $20 \mathrm{~h} /$ week) and symptoms of CTS. ${ }^{16}$ Some countries, including France, consider CTS to be potentially caused by computer use at work, so computer workers with CTS are eligible for compensation by Workers' Compensation Insurance. ${ }^{8} 17$ 
We set out to explore the possible association between computer use and CTS using longitudinal data from two large cohorts, one from Europe and one from the USA. Each study used a specific case definition of CTS and followed participants for several years.

\section{METHODS}

\section{Design}

Analyses were performed on two complementary worker cohorts from the Cosali and PrediCTS studies (table 1). The Cosali cohort was a representative sample of a French working population with a case definition of CTS based on a standardised clinical exam ${ }^{4}$ and exposure based on self-reported computer use. The PrediCTS cohort study enrolled newly hired clerical, service and construction workers in several industries in the USA, with a case definition based on symptoms and nerve conduction studies (NCS) at baseline and follow-up. Computer work exposures were based on a job exposure matrix derived from a national database of work requirements linked to standardised job codes. ${ }^{18}$

\section{Study populations}

The Cosali cohort

The Cosali study (Cohorte des Salariés Ligériens, Principal Investigator YR) gathered data prospectively on a large sample of workers from the Loire Valley area of West Central France. This area represents 5.6\% of the French workforce, whose demographic characteristics and distribution of employment are similar to that of the national workforce. ${ }^{19} 20$ At the time of the first survey, all salaried employees in France, including temporary and part-time workers, were required to undergo a mandatory annual health examination by a qualified occupational physician. Each physician was in charge of the medical surveillance of a group of companies. Participants were randomly selected from workers aged between 20 and 59 years who underwent an annual health examination between April 2002 and April 2005 by 1 of the 83 regional occupational physicians who volunteered to recruit workers to the study. The distributions of jobs and industries among the participants were similar to those of the region. Participants filled out selfadministered questionnaires before each health examination. They were invited to receive a repeat examination between 2007 and 2010.

\section{The PrediCTS cohort}

The Predictors of Carpal Tunnel Syndrome study (PrediCTS, Principal Investigator BAE) enrolled 1107 newly employed workers from eight companies and three construction trade unions in the St Louis region of the USA; baseline examinations were completed between July 2004 and October 2006. ${ }^{21}$ Inclusion criteria required a minimum age of 18 years, ability to speak English, working at least $30 \mathrm{~h} /$ week, and being newly hired or benefits eligible within the prior 30 days. Participants were ineligible at baseline if they were pregnant, had a history of CTS or peripheral neuropathy, or had another contraindication for NCS. Workers underwent physical examinations of the distal upper limbs and bilateral NCS of the wrists at baseline with re-evaluation between 3 and 5 years later. All participants completed surveys about demographics, employment and medical histories at baseline and follow-up. ${ }^{22}$

\section{Case definition}

\section{The Cosali cohort}

Participants who reported upper-limb symptoms by selfadministered surveys during the previous 12 months received a physical examination using a standardised clinical procedure and performed by an occupational physician. ${ }^{4}$ All occupational physicians participated in a $3 \mathrm{~h}$ training programme to learn the standardised clinical procedures and received a copy of the guidelines (including diagnostic criteria charts and photographs of clinical

Table 1 Main characteristics of the Cosali and PrediCTS cohorts

\begin{tabular}{|c|c|c|}
\hline & Cosali & PrediCTS \\
\hline Recruiting area & Loire Valley area of West Central, France & St. Louis area, USA \\
\hline Recruiting period & April 2002-2005 & July 2004-October 2006 \\
\hline Years of follow-up & 2007-2010 & 2007-2011 \\
\hline \multirow[t]{4}{*}{ Occupational sectors } & Agriculture & Clerical \\
\hline & Industry & Services \\
\hline & Services & Construction \\
\hline & Construction & \\
\hline Number of participants included in the cohort & 3710 & 1107 \\
\hline Number of participants included in the analysis & $1551(41.8 \%)$ & $711(64.2 \%)$ \\
\hline \multicolumn{3}{|l|}{ CTS definition } \\
\hline Standardised physical examination at baseline & Yes & Yes \\
\hline Nerve conduction studies at baseline & No & Yes \\
\hline Work exposures assessment & Self-administrated questionnaire & Job exposure matrix \\
\hline Representativeness of the population of workers & Yes & No \\
\hline Consideration of confounders & Yes & Yes \\
\hline
\end{tabular}


tests) ${ }^{23}$ A case definition of CTS included the presence of symptoms on the day of the medical examination or for at least 4 days during the preceding 7 days and a positive physical sign. Symptoms were defined as intermittent paresthaesia or pain in at least two of the first three digits (thumb, index or middle finger), potentially with pain at night in the palm, wrist or radiating proximally to the wrist, plus a positive result on at least one of the following tests: flexion or carpal compression test, Tinel's or Phalen's test, static two-point discrimination, or resisted thumb abduction or observed atrophy of the abductor pollicis brevis muscle. Participants were considered a CTS case if they met the case definition for either hand.

\section{The PredicTS cohort}

All participants underwent physical exams and bilateral NCS of the hand and completed surveys to describe hand symptoms. The CTS case definition required median nerve symptoms and abnormal NCS findings during follow-up testing. ${ }^{24}$ Median nerve symptoms included numbness, tingling, burning or pain in at least one of the first three digits. Participants indicated the location and description of symptoms on a hand diagram. The CTS case definition required symptoms and abnormal NCS.

NCS were conducted by trained technicians using the NC-stat automated testing device (NEUROMetrix, Inc., Waltham, Massachusetts, USA). ${ }^{25}$ All NCS values were temperature-adjusted to $32^{\circ} \mathrm{C}$ based on the manufacturer's recommendations. The distal sensory latencies (DSL) were length-adjusted to a standard $14 \mathrm{~cm}$ distance between the stimulus and response electrodes. Criteria for abnormal NCS were median distal motor latency of greater than $4.5 \mathrm{~ms}$, median DSL of greater than $3.5 \mathrm{~ms}$ or median-ulnar sensory latency difference of greater than $0.5 \mathrm{~ms} .{ }^{26}$ Absent DSL values were considered abnormal. Participants were counted as a CTS case if they met the case definition for either hand. Prevalent cases of CTS at baseline were excluded from the analysis.

\section{Computer work exposure assessment \\ The Cosali cohort}

Exposure to computer work was assessed at baseline with several questions. One question was asked on all surveys: "During a typical day at work, do you use a computer screen or control screen", with the answer to be chosen from four categories: Never or almost never, Less than $2 \mathrm{~h} /$ day, $2-4 \mathrm{~h} /$ day, and all or almost all of the working day. Two other questions specific to the type of computer device used changed over the years of data collection. Initially, the question asked about the keyboard and mouse with the later question adding other input devices (light pen, scanner, barcode reader...). These items were combined across surveys and the response was entered in a separate model as a sensitivity analysis.

\section{The PrediCTS cohort}

Work exposures were based on a job-exposure matrix that contained standardised occupational codes and associated exposure values from the Occupational Network $(\mathrm{O} *$ NET $) .{ }^{18} \mathrm{O} *$ NET data are a compilation of item responses from randomly selected workers and/or job analysts, summarised within each job code. The O*NET item pertaining to computer use was described as follows: "Working with Computers: using computers and computer systems (including hardware and software) to programme, write software, set up functions, enter data, or process information." This question was scored on a five point scale of "How important is working with computer to the performance of your current job?" The five point response scale ranged from not important (1) to extremely important (5). Since there were no jobs with a response for level 5 , the exposure scale was based on four levels, similar to the four levels from the Cosali study.

\section{Personal factors and medical history assessment}

Personal factors and medical history were recorded at baseline with self-administrated surveys in each cohort. The variables used for this study were: age, sex, obesity (defined as body mass index-BMI $\geq 30 \mathrm{~kg} / \mathrm{m}^{2}$ ) and associated medical disorders (thyroid disorders, rheumatoid arthritis or diabetes mellitus). ${ }^{27}$ These associated disorders were completed by the physician from the patient's history taken during the clinical examination in the Cosali cohort, and were self-reported in the PrediCTS study. Although there is new evidence about anthropometric measures that might be used for CTS screening, ${ }^{28}$ obesity defined by BMI over $30 \mathrm{~kg} / \mathrm{m}^{2}$ was considered the most relevant anthropometric factor to adjust on. Alcohol and tobacco use were included in the initial analyses, not considered as significant risk factors for CTS. ${ }^{29} 30$

\section{Statistical analyses}

Similar statistical analyses were performed separately with the data from each cohort. An outcome of CTS for each subject was defined as a unilateral or bilateral diagnosis of CTS. The relationship between CTS and computer use exposure was studied with logistic regression models adjusting for demographic and clinical variables. Univariate analyses were performed to describe the relationship between each explanatory variable and the outcomes. Multivariate logistic regression analyses included all explanatory variables to account for risk factors and potential confounders in the relationship between computer use and CTS. For the Cosali cohort, a comparison of the response to the two computer use items showed strong agreement $(\kappa 0.91)$.

For each cohort, several sensitivity analyses were performed to examine differences in results: use of input devices versus general computer use (Cosali cohort only), BMI as a continuous variable, male versus female sex stratified in the analysis, and restricting the analysis 
to participants who had not changed their job throughout the follow-up period. In the Cosali cohort, the Borg Rating of Perceived Exertion Scale, ranging from 6 to 20 and dichotomised into less than hard exertion (6-13) and hard exertion to exhaustion (14-20), was used to study associations between hard exertion to exhaustion and daily duration of computer use. In the PredictS study, tasks involving office work were described specifically.

Considering the importance of attrition in the Cosali cohort, we ran simulations to test the hypothetic associations between CTS and computer work among participants lost to follow-up to see whether the estimates would be as strong as results from a previous publication by Andersen et $a l^{16}$ (OR Right-handed mouse use, $>20 \mathrm{~h} /$ week $2.6(1.2-5.5))$. Significance was defined by a $\mathrm{p}$ value of 0.05 . Analyses were performed with the SAS statistical software package (V.9.3: SAS Institute. Inc., Cary, North Carolina, USA).

All participants provided informed written consent. For the Cosali cohort, the study received approval from
Figure 1 Flow chart for the actual study in the Cosali cohort. CTS, carpal tunnel syndrome; $\mathrm{OP}$, occupational physician.
France's National Committee for Data Protection (Commission Nationale de l'Informatique et des Libertés). For the PrediCTS cohort, the study was approved by the Institutional Review Board of Washington University in St. Louis.

\section{RESULTS}

The Cosali cohort recruited 3710 participants and completed follow-up on $41.8 \%$ of the participants (figure 1). The PrediCTS cohort enrolled 1107 participants at baseline; $711(64.2 \%)$ had complete exposure and outcome data at follow-up, and did not have prevalent CTS at baseline (figure 2). Comparing participants who completed the follow-up visit with participants lost to follow-up in the Cosali cohort, a prior publication showed that those followed were older and employed for a longer period in the initial job, with fewer temporary workers and workers employed in the agriculture sector. ${ }^{20}{ }^{31}$ For the PrediCTS cohort, there were no statistically significant differences at baseline for age,

Baseline
2002-2005

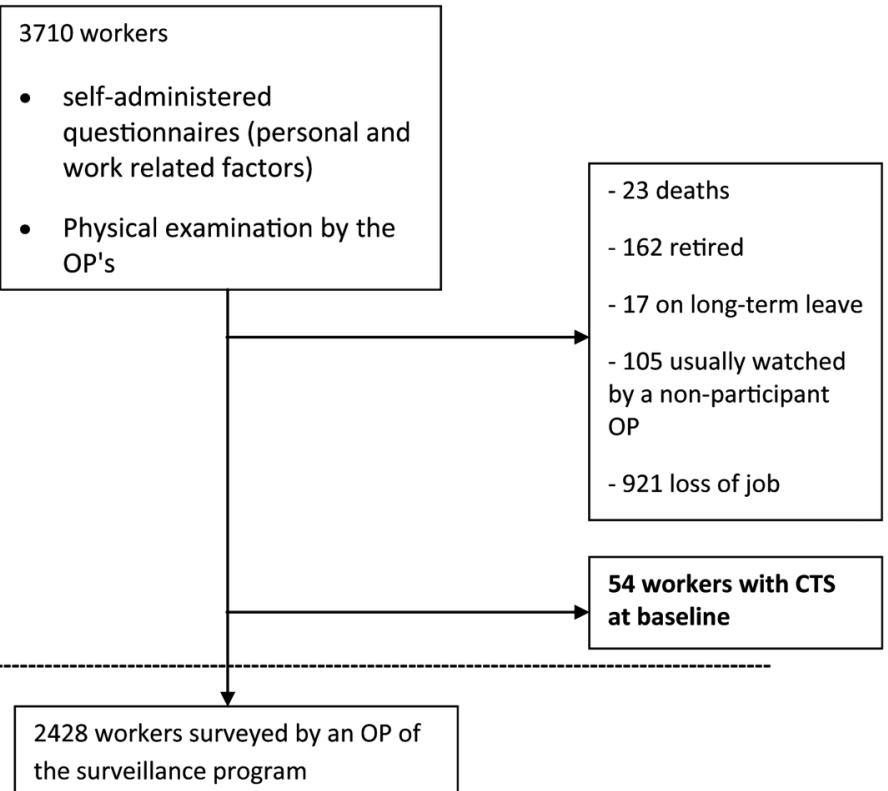

2007-2010

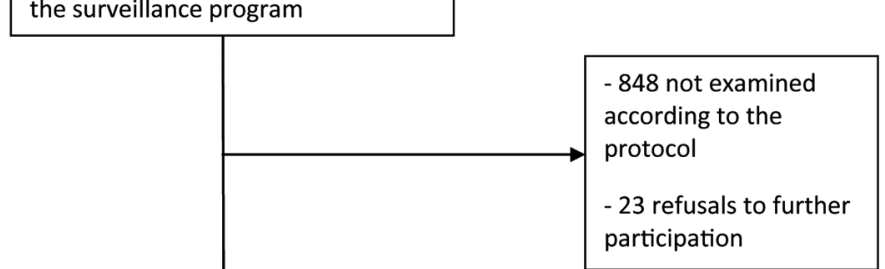

1557 workers regularly seen during

scheduled health examination

6 workers with unknown CTS status 
gender, body mass index, medical history or baseline job category between those with follow-up data and those lost to follow-up. ${ }^{32}$ Similar group comparisons showed no difference in prevalent CTS between those followed or lost to follow-up in either cohort. Both cohorts were predominantly male. Participants were primarily employed in service $(56.9 \%)$ and clerical $(37.3 \%)$ jobs for the Cosali cohort, while they were more often employed in construction $(40.8 \%)$ and clerical jobs $(36.9 \%)$ at baseline for the Predicts study. As summarised in table 2, the subject's age ranged between 20 and 59 years in the Cosali cohort, while more than $50 \%$ of the PrediCTS participants were aged less than 30 years.

There were $36(2.3 \%)$ cases of incident CTS in one or both hands in the Cosali cohort and $31(4.3 \%)$ in the PredicTS cohort. Few of the cases of CTS were employed in jobs described as clerical positions; three cases from the Cosali cohort reported work in banking or accounting; two cases in the PrediCTS study were employed as a staff coordinator and an office administrator. The Cosali cohort also had five participants with CTS employed in jobs that could not be assigned to a specific type of work based on their job titles: employee, employee of public sector, intermediate sector. Table 3 shows the univariate and multivariate logistic regression results. Univariate results showed significant associations with CTS for sex in the Cosali cohort and obesity in the PrediCTS cohort. Multivariate analyses that adjusted for age, sex, obesity and the presence of a medical condition showed that reported exposure to computer work was not a risk factor for CTS.

In the Cosali study, the sensitivity analysis that included the type of input device used for computer work like keyboard, mouse, light pen, scanner and barcode reader rather than the time spent viewing the computer screen showed nearly identical results (univariate results: $\mathrm{OR}_{<2} \mathrm{~h}$ $0.7(0.3 ; 1.9), \mathrm{OR}_{<2-4 \mathrm{~h}} 0.1(0.0 ; 1.1), \mathrm{OR}_{\text {almost all the time }}$ $0.5(0.2 ; 1.2)$; multivariate results adjusting for the same factor as shown in table 3 : $\mathrm{OR}_{<2 \mathrm{~h}} 0.8(0.3 ; 2.0), \mathrm{OR}_{<2-4 \mathrm{~h}}$ $\left.0.2(0.0 ; 1.1), \mathrm{OR}_{\text {almost all the time }} 0.4(0.2 ; 1.0)\right)$. There was no difference in models for either cohort with using BMI instead of a dichotomised value for obesity. Sensitivity analysis distinguishing men and women, and participants who kept the same job since the beginning of the study did not modify the results in either cohort. In the Cosali cohort, hard exertion to exhaustion decreased with increased computer use: among participants reporting computer use of never or almost never, $74.4 \% \quad(\mathrm{n}=326)$ reported hard exertion to exhaustion; among those reporting computer use of less than $2 \mathrm{~h} /$ day $61.6 \%$ $(\mathrm{n}=109)$ reported hard exertion, for $2-4 \mathrm{~h}$ of computer use per day $35.5 \%(\mathrm{n}=59)$, and among those reporting computer use almost all of the working day, only $15.7 \%$
Figure 2 Flow chart for the PrediCTS cohort. CTS, carpal tunnel syndrome; OP, occupational physician.

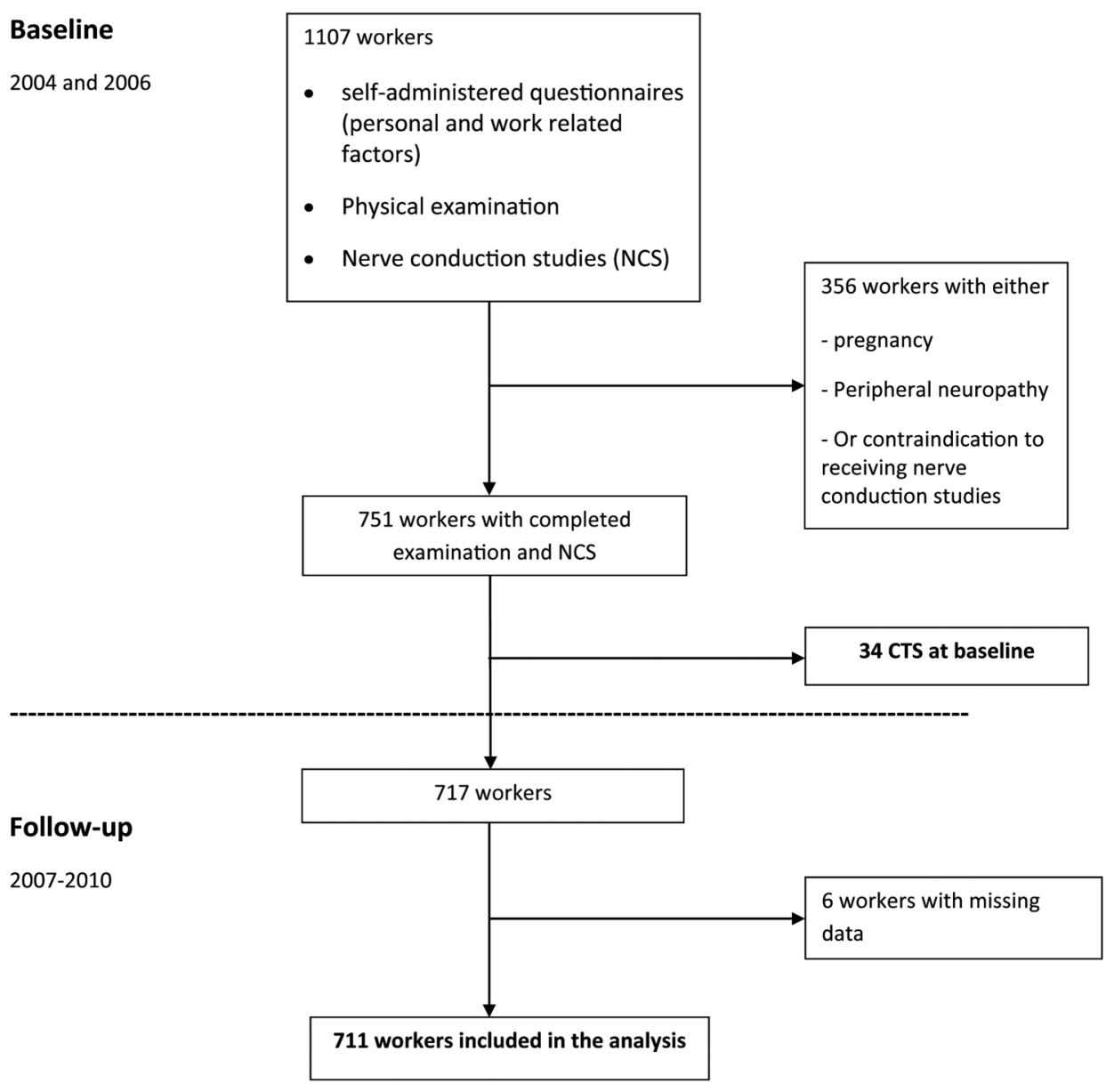


Table 2 Demographic and clinical characteristics of the study population for both cohorts

\begin{tabular}{|c|c|c|c|c|}
\hline \multirow[b]{2}{*}{ Characteristic } & \multicolumn{2}{|c|}{$\begin{array}{l}\text { Cosali } \\
n=1551\end{array}$} & \multicolumn{2}{|c|}{$\begin{array}{l}\text { PredicTS } \\
\mathrm{n}=711\end{array}$} \\
\hline & $\mathbf{n}$ & Per cent & $\mathrm{n}$ & Per cent \\
\hline \multicolumn{5}{|l|}{ Age (years) } \\
\hline$<30$ & 271 & 17.5 & 412 & 57.9 \\
\hline 30-39 & 513 & 33.1 & 145 & 20.4 \\
\hline $40-49$ & 583 & 37.6 & 97 & 13.6 \\
\hline$\geq 50$ & 182 & 11.7 & 57 & 8 \\
\hline \multicolumn{5}{|l|}{ Gender } \\
\hline Male & 893 & 57.6 & 458 & 64.4 \\
\hline Female & 658 & 42.4 & 253 & 35.6 \\
\hline \multicolumn{5}{|l|}{ Body mass index } \\
\hline$<18.5 \mathrm{~kg} / \mathrm{m}^{2}$ & 57 & 3.7 & 12 & 1.7 \\
\hline $18.5-24.9 \mathrm{~kg} / \mathrm{m}^{2}$ & 921 & 59.4 & 231 & 32.5 \\
\hline $25-29.9 \mathrm{~kg} / \mathrm{m}^{2}$ & 439 & 28.3 & 237 & 33.3 \\
\hline$\geq 30 \mathrm{~kg} / \mathrm{m}^{2}$ & 112 & 7.2 & 231 & 32.5 \\
\hline Thyroid disorders & 59 & 3.8 & 15 & 2.1 \\
\hline Diabetes mellitus & 17 & 1.1 & 16 & 2.3 \\
\hline Rheumatoid arthritis & 28 & 1.8 & 10 & 1.4 \\
\hline
\end{tabular}

$(n=55) \quad(p<0.0001)$. Office workers had fewer new CTS cases than other work groups: $1.7 \% \quad(n=3,1$ man, 2 women, $\mathrm{p}=0.052$ ).

The hypothetical modelised OR between CTS and computer work among the participants who were lost to follow-up produced an OR of more than 10 (simulated OR) in the Cosali study (and 73 in the PrediCTS study), which is much higher than the value found in a previous study by Andersen et al (OR: 2.6).

\section{DISCUSSION}

This study evaluated the potential relationship between computer use and CTS using simple measures of computer use (time spent at the computer and the importance of computer use in the job) and found no association in two separate prospective cohort studies. Few of the workers employed in jobs dominated by computer use developed CTS. Both cohorts included workers from many different industries whose tasks involved various other biomechanical exposures (ie, hand force, repetition, vibration) that have previously been associated with CTS. Within these diverse working populations, any association between using a computer and CTS was too small to be detected.

There were some limitations to this study. In the Cosali cohort, only $41.8 \%$ of the baseline cohort participants remained in the follow-up assessment. This attrition parallels the decline in employment observed in the region during the economic crisis of this period, with a reduction in employment by $3.4 \%$ of regular workers and $33.7 \%$ in temporary employment agencies. $^{31}$ The lowest participation rate was among young workers, workers in temporary employment and those with a short length of service. Even though this situation might affect the incidence of musculoskeletal disorders, ${ }^{33}$ its impact was unlikely to have a major effect on the observed exposure associations. ${ }^{34}$ Furthermore, the simulations to compute hypothetical estimates of associations between CTS and computer work among participants lost to follow-up indicated that unrealistically high risks of CTS associated with computer work would be needed in these participants to affect the results. In addition, a prior study of workers with CTS showed that few patients leave their jobs following a diagnosis of CTS. ${ }^{35}$

The case definition in the Cosali cohort did not include NCS, which are generally recommended for improving diagnostic accuracy, and could potentially have led to some disease misclassification. Previous comparisons between different case definitions of CTS showed relatively good agreement, including agreement between the case definition used in the Cosali cohort and a definition including NCS. ${ }^{36}{ }^{37}$ Furthermore, the two independent studies showed similar associations despite using two different case definitions of CTS.

It is unclear how much misclassification may have been introduced by the measures used to assess the exposure to computer use. ${ }^{38} 39$ In the Cosali cohort, a self-administered questionnaire was used to assess computer use during a typical workday in the preceding 12-month period, and awkward postures were presented to the subjects in a diagram or picture to facilitate the participants' understanding, and increase the reliability of self-assessment of posture. There was very high concordance (over $0.9 \kappa$ value) between exposures defined as viewing a computer screen and as use of data entry devices. Furthermore, Ijmker et $a t^{40}$ compared selfreported assessment of computer use to measured use. In spite of the low correlation between the two assessment methods ( $r$ 0.2), neither method showed an association between computer use and musculoskeletal symptoms. ${ }^{41} 42$ The PrediCTS cohort used a job exposure matrix based on exposure values from the Occupational Network $\left(\mathrm{O}^{*}\right.$ NET $)$ database. O*NET is a publicly available online database that describes occupational demands across US job titles; it has recently been used successfully to estimate workplace physical and psychosocial exposures and organisational characteristics in epidemiology studies. ${ }^{17} 43$ However, the computerrelated item from $\mathrm{O}^{*} \mathrm{NET}$, "How important is working with computers to the performance of your current job?", does not specifically address the biomechanical factors for the intensity, duration or work positions of computer work tasks. In addition, the question in the Cosali study did not differentiate exposures from various input devices (keyboard, mouse, stylus). Although exposure misclassification, confounding or other interactions may have modified the observed associations in both cohorts, very large effects would be required for computer use to constitute a risk factor for CTS among our study populations.

Preliminary analyses found that forceful work exposures and computer work exposures were strongly negatively 
Table 3 Univariate and multivariate models for risk factors of incident CTS in both cohorts

\begin{tabular}{|c|c|c|c|c|c|c|c|c|c|c|}
\hline & \multicolumn{5}{|c|}{ Cosali cohort } & \multicolumn{5}{|c|}{ PREDICTS cohort } \\
\hline & $\mathbf{N}$ & nCTS & \%CTS & OR crude & $\begin{array}{l}\text { OR adjusted } \\
\text { (variables showed) }\end{array}$ & $\mathbf{N}$ & CTS & \%CTS & OR crude & $\begin{array}{l}\text { OR adjusted } \\
\text { (variables showed) }\end{array}$ \\
\hline \multicolumn{11}{|l|}{ Age (years). } \\
\hline$<30$ & 271 & 3 & 1.11 & 1.00 & 1.00 & 412 & 14 & 3.4 & 1.00 & 1.00 \\
\hline $0-39$ & 513 & 13 & 2.53 & $2.32(0.66 ; 8.22)$ & $2.42(0.68 ; 8.62)$ & 145 & 6 & 4.14 & $1.23(0.46 ; 3.26)$ & $1.19(0.44 ; 3.25)$ \\
\hline $40-49$ & 583 & 14 & 2.4 & $2.20(0.63 ; 7.71)$ & $2.06(0.58 ; 7.32)$ & 97 & 6 & 6.19 & $1.87(0.70 ; 5.01)$ & $1.11(0.36 ; 3.41)$ \\
\hline$\geq 50$ & 182 & 6 & 3.3 & $3.04(0.75 ; 12.33)$ & $2.93(0.71 ; 12.20)$ & 57 & 5 & 8.77 & $2.73(0.95 ; 7.90)$ & $1.49(0.42 ; 5.28)$ \\
\hline \multicolumn{11}{|l|}{ Sex } \\
\hline Male & 893 & 11 & 1.23 & 1.00 & 1.00 & 458 & 18 & 3.93 & 1.00 & 1.00 \\
\hline Female & 658 & 25 & 3.8 & $3.17(1.55 ; 6.48)^{\star}$ & $3.24(1.56 ; 6.73)^{\star}$ & 253 & 13 & 5.14 & $1.32(0.64 ; 2.75)$ & $1.74(0.73 ; 4.11)$ \\
\hline \multicolumn{11}{|c|}{ Body mass index $\left(\mathrm{kg} / \mathrm{m}^{2}\right)$} \\
\hline$<18.5$ & 57 & 2 & 3.51 & $1.49(0.34 ; 6.48)$ & & 12 & 1 & 8.33 & $6.91(0.66 ; 71.91)$ & \\
\hline $18.5-24.9$ & 921 & 22 & 2.39 & 1.00 & & 231 & 3 & 1.3 & 1.00 & \\
\hline $25-29.9$ & 439 & 7 & 1.59 & $0.66(0.28 ; 1.56)$ & & 237 & 10 & 4.22 & $3.35(0.91 ; 12.32)$ & \\
\hline$\geq 30$ & 112 & 5 & 4.46 & $1.91(0.71 ; 5.15)$ & & 231 & 17 & 7.36 & $6.04(1.74 ; 20.89)^{\star}$ & \\
\hline \multicolumn{11}{|c|}{ Obesity $\left(\mathrm{kg} / \mathrm{m}^{2}\right)$} \\
\hline$\leq 30$ & 1439 & 31 & 2.15 & 1.00 & 1.00 & 480 & 14 & 2.92 & 1.00 & 1.00 \\
\hline$>30$ & 112 & 5 & 4.46 & $2.12(0.81 ; 5.57)$ & $1.89(0.70 ; 5.13)$ & 231 & 17 & 7.36 & $2.64(1.28 ; 5.46)^{\star}$ & $1.89(0.84 ; 4.25)$ \\
\hline \multicolumn{11}{|c|}{ Thyroid disorders } \\
\hline No & 1485 & 35 & 2.36 & 1.00 & & 696 & 30 & 4.31 & 1.00 & \\
\hline Yes & 59 & 1 & 1.69 & $0.71(0.10 ; 5.30)$ & & 15 & 1 & 6.67 & $1.59(0.20 ; 12.46)$ & \\
\hline \multicolumn{11}{|c|}{ Diabetes mellitus } \\
\hline No & 1526 & 35 & 2.29 & 1.00 & & 695 & 29 & 4.17 & 1.00 & \\
\hline Yes & 17 & 1 & 5.88 & $2.66(0.34 ; 20.64)$ & & 16 & 2 & 12.5 & $3.28(0.71 ; 15.11)$ & \\
\hline \multicolumn{11}{|c|}{ Rheumatism arthritis } \\
\hline No & 1515 & 35 & 2.31 & 1.00 & & 701 & 30 & 4.28 & 1.00 & \\
\hline Yes & 28 & 1 & 3.57 & $1.57(0.21 ; 11.85)$ & & 10 & 1 & 10 & $2.49(0.30 ; 20.26)$ & \\
\hline \multicolumn{11}{|c|}{ Thyroid disorders or diabetes or arthritis } \\
\hline No & 1458 & 33 & 2.26 & 1.00 & 1.00 & 672 & 27 & 4.02 & 1.00 & 1.00 \\
\hline Yes & 93 & 3 & 3.23 & $1.44(0.43 ; 4.78)$ & $0.90(0.25 ; 3.15)$ & 39 & 4 & 10.26 & $2.73(0.91 ; 8.23)$ & $2.37(0.70 ; 7.99)$ \\
\hline \multicolumn{11}{|c|}{ Computer work exposure $†$} \\
\hline 1 & 611 & 22 & 3.6 & 1.00 & 1.00 & 355 & 23 & 6.48 & 1.00 & 1.00 \\
\hline 2 & 234 & 5 & 2.14 & $0.58(0.22 ; 1.56)$ & $0.60(0.22 ; 1.63)$ & 77 & 2 & 2.6 & $0.38(0.09 ; 1.67)$ & $0.38(0.09 ; 1.67)$ \\
\hline 3 & 219 & 1 & 0.46 & $0.12(0.02 ; 0.92)^{\star}$ & $0.13(0.02 ; 1.01)$ & 52 & 1 & 1.92 & $0.28(0.04 ; 2.14)$ & $0.20(0.03 ; 1.62)$ \\
\hline 4 & 482 & 8 & 1.66 & $0.45(0.20 ; 1.02)$ & $0.39(0.17 ; 0.89)^{\star}$ & 202 & 3 & 1.49 & $0.22(0.06 ; 0.73)^{\star}$ & $0.16(0.05 ; 0.59)^{\star}$ \\
\hline
\end{tabular}


associated, so jobs were dominated by one exposure more than the other. In the Cosali study, hard exertion to exhaustion decreased with the increased daily duration of computer use, and office workers had a relatively lower proportion of new CTS than other jobs in the PrediCTS cohort. Since the cohorts contained workers from a wide range of jobs but only the exposure for computer use was added to the models, the OR below 1.0 suggests that workers in jobs requiring computer use have a lower incidence of CTS than workers with other occupational risk factors that were not included in the model. Computer work involves various tasks and durations of exposure, including keyboarding/typing and use of a computer mouse in different work situations. In some companies, computer work may involve awkward sustained postures or other conditions which may be associated with an increased CTS risk. The low associations seen in our two cohorts suggest that the risk found for computer work in general is less important compared to the risk factors for CTS found in other job sectors.

The strengths of both cohorts were their prospective, longitudinal study design and the rigorous case definitions of incident CTS cases. Each cohort had specific strengths: the Cosali cohort was representative of a French region's working population and used standardised questions specific to computer duration exposure, whereas the PrediCTS study followed a large group of workers over a long period of time with low attrition, and used a robust case definition that included NCS. These studies have different methodologies and populations that made it undesirable to pool the data from the two samples; however, the similar association values found in the two studies is noteworthy.

Other studies have found similar results. Atroshi et $a l^{44}$ conducted a cross-sectional study on 2465 participants aged between 25 and 65 years randomly selected from the population register of south Sweden. The results showed a similar pattern with no significant associations between CTS and the duration of daily computer use $\left(\mathrm{OR}_{<1 \mathrm{~h} / \text { day }}\right.$ $0.9(0.5 ; 1.7)$, OR1-4 h/day $0.6(0.2-1.2) \quad \mathrm{OR}_{>4 \mathrm{~h}} 0.5(0.2-$ 1.2)). Thomsen et $a l^{45}$ found a positive association between computer work and CTS in a cross-sectional analysis, and they had only two incident cases and were thus unable to conduct the longitudinal study. Andersen $e t a l^{16}$ conducted a longitudinal study with a 1-year follow-up in a cohort of 9480 participants recruited from a Danish trade union of technicians. At the 1-year follow-up, case definitions based on the presence of new or worsened symptoms showed that the incidence of possible righthand CTS was $5.5 \% \quad(n=198)$ and the onset of possible CTS was associated with mouse use. However, the use of case definition based solely on symptoms may have created a misclassification of cases, ${ }^{46}$ and the authors concluded that "computer use did not pose a severe occupational hazard for developing symptoms of CTS."

In conclusion, two large prospective cohort studies from different countries found that computer work was associated with lowered risks of CTS when compared to workers across multiple industries. This study does not rule out the possibility that specific biomechanical exposures in some types of computer work may increase the risk for CTS, especially within worker groups without exposure to any other hand-intensive work. It is important to improve any work conditions that place computer workers in sustained awkward postures or lead to other symptoms; surveillance of workers using new technologies is also necessary. However, compensation programmes for work-related disorders should recognise that computer users are at lower risk for CTS compared to workers in food processing, manufacturing, service work, construction and other occupations where repeated or sustained exposures to forceful hand exertions pose a strong increased risk for CTS. ${ }^{47}$

\section{Author affiliations}

${ }^{1}$ Inserm, Population-Based Epidemiological Cohorts Unit, UMS 011, Villejuif, France

${ }^{2}$ Versailles St-Quentin University, UMS 011, Villejuif, France

${ }^{3}$ AP-HP, Occupational Health Unit/EMS (Samu92), University hospital of West suburb of Paris, Poincaré site, Garches, France

${ }^{4}$ Laboratory of Ergonomics and Epidemiology in Occupational Health (LEEST), LUNAM University, University of Angers, Angers, France

${ }^{5}$ Division of General Medical Sciences, Washington University School of Medicine, St. Louis, Missouri, USA

${ }^{6}$ Inserm, UMR-S VIMA, Villejuif, France

${ }^{7}$ Department of Occupational Health, French Institute for Public Health

Surveillance, Saint-Maurice, France

${ }^{8}$ Hand Center, Clinique les eaux claires, ZAC Moudong Sud, Baie Mahault, France

${ }^{9} \mathrm{CHU}$ Angers, Angers, France

Acknowledgements The authors would like to thank all physicians who participated in the Cosali study.

Contributors All authors had substantial contributions to the conception or design of the work; or the acquisition, analysis or interpretation of data for the work. In particular, AMD initiated the work and chose the study design, and $B A E$ and AMD were responsible for data collection of PrediCTS and its analysis. NF, JB and YR were responsible for data collection in the Cosali study, and its analysis. For the actual study, data analyses were performed by $E H$ and $A D$ under the supervision of $C D$ and $M C$. ZM was responsible for the first draft. All authors revised it critically for important intellectual content. AMD included all the comments for the final draft. All authors approved the final manuscript.

Funding The PrediCTS study was supported by CDC/NIOSH (grant \# R010H008017) and by the Washington University Institute of Clinical and Translational Sciences Award (CTSA) (grant \# UL1 TR000448) from the National Center for Advancing Translational Sciences (NCATS) of the National Institutes of Health (NIH). Its contents are solely the responsibility of the authors and do not necessarily represent the official view of NIOSH, NCATS or $\mathrm{NIH}$. The Cosali study was supported by the French Institute for Public Health Surveillance, Saint-Maurice, France (Grant 9/25/2002-5 " réseau expérimental de surveillance des troubles musculo-squelettiques ", "étude du pronostic médical et professionnel de certains TMS à partir des données du réseau pays de la Loire "), the French National Research Agency (Grant sponsor: ANR; Grant number: SEST-06-36. HUPIFO (Paris Hospital) and CRAMIF also supported the study ("etude action 2015-6").

Competing interests None declared.

Patient consent Obtained.

Ethics approval All participants provided informed written consent. For the PrediCTS cohort, the study was approved by the Institutional Review Boards 
of the Washington University in St. Louis School of Medicine. For the Cosali cohort, the study received approval from France's National Committee for Data Protection (Commission Nationale de l'Informatique et des Libertés). Data used for the two studies might be requested from the two primary investigators, Prof Roquelaure (Cosali) and Prof Evanoff (PrediCTS)

Provenance and peer review Not commissioned; externally peer reviewed.

Data sharing statement Data used for the two studies might be asked to the two PI, Prof Roquelaure (Cosali) yvroquelaure@chu-angers.fr and Prof Evanoff (PrediCTS) bevanoff@dom.wustl.edu.

Open Access This is an Open Access article distributed in accordance with the Creative Commons Attribution Non Commercial (CC BY-NC 4.0) license, which permits others to distribute, remix, adapt, build upon this work noncommercially, and license their derivative works on different terms, provided the original work is properly cited and the use is non-commercial. See: http:// creativecommons.org/licenses/by-nc/4.0/

\section{REFERENCES}

1. Atroshi I, Gummesson C, Johnsson R, et al. Prevalence of carpal tunnel syndrome in a general population. JAMA 1999;282:153-8.

2. Roquelaure $\mathrm{Y}, \mathrm{Ha} \mathrm{C}$, Pelier-Cady $\mathrm{MC}$, et al. Work increases the incidence of carpal tunnel syndrome in the general population. Muscle Nerve 2008;37:477-82.

3. Bernard BP, Putz-Anderson V, Musculoskeletal disorders and workplace factors: a critical review of epidemiologic evidence for work-related musculoskeletal disorders of the neck, upper extremity, and low back. Published Online First: 1997. http://stacks.cdc.gov/ view/cdc/21745 (accessed 29 Jul 2014).

4. Sluiter JK, Rest KM, Frings-Dresen MH. Criteria document for evaluating the work-relatedness of upper-extremity musculoskeletal disorders. Scand J Work Environ Health 2001;27(Suppl 1):1-102.

5. van Rijn RM, Huisstede BM, Koes BW, et al. Associations between work-related factors and the carpal tunnel syndrome-a systematic review. Scand J Work Environ Health 2009;35:19-36.

6. Palmer KT. Carpal tunnel syndrome: the role of occupational factors Best Pract Res Clin Rheumatol 2011;25:15-29.

7. Gerr F, Marcus M, Ensor C, et al. A prospective study of computer users: I. Study design and incidence of musculoskeletal symptoms and disorders. Am J Ind Med 2002;41:221-35.

8. Cail F, Aptel M. Facteurs de risque pour le membre supérieur dans le travail sur écran: synthèse bibliographique. Trav Hum 2006;69:229-68.

9. Barcenilla A, March LM, Chen JS, et al. Carpal tunnel syndrome and its relationship to occupation: a meta-analysis. Rheumatol Oxf Engl 2012;51:250-61.

10. Thomsen JF, Gerr F, Atroshi I. Carpal tunnel syndrome and the use of computer mouse and keyboard: a systematic review. BMC Musculoskelet Disord 2008;9:134.

11. Andersen JH, Fallentin N, Thomsen JF, et al. Risk factors for neck and upper extremity disorders among computers users and the effect of interventions: an overview of systematic reviews. PLOS ONE 2011;6:e19691.

12. Palmer KT, Harris EC, Coggon D. Carpal tunnel syndrome and its relation to occupation: a systematic literature review. Occup Med Lond 2007;57:57-66.

13. Waersted M, Hanvold TN, Veiersted KB. Computer work and musculoskeletal disorders of the neck and upper extremity: a systematic review. BMC Musculoskelet Disord 2010;11:79.

14. Mediouni Z, de Roquemaurel A, Dumontier C, et al. Is carpal tunnel syndrome related to computer exposure at work? A review and meta-analysis. J Occup Environ Med 2014;56:204-8.

15. Shiri R, Falah-Hassani K. Computer use and carpal tunnel syndrome: a meta-analysis. J Neurol Sci 2015;349:15-19.

16. Andersen JH, Thomsen JF, Overgaard E, et al. Computer use and carpal tunnel syndrome: a 1-year follow-up study. JAMA 2003;289:2963-9.

17. Mediouni $Z$, Descatha $A$. Le travail sur ordinateur est-il associé au syndrome du canal carpien ? Arch Mal Prof Environ 2014:75:125.

18. Evanoff $B$, Zeringue A, Franzblau A, et al. Using job-title-based physical exposures from O*NET in an epidemiological study of carpal tunnel syndrome. Hum Factors 2014;56:166-77.

19. Roquelaure $\mathrm{Y}, \mathrm{Ha} \mathrm{C}$, Leclerc $\mathrm{A}$, et al. Epidemiologic surveillance of upper-extremity musculoskeletal disorders in the working population. Arthritis Rheum 2006;55:765-78.

20. Bodin J, Ha C, Petit Le Manac'h A, et al. Risk factors for incidence of rotator cuff syndrome in a large working population. Scand $J$ Work Environ Health 2012;38:436-46.
21. Gardner BT, Dale AM, Vandillen L, et al. Predictors of upper extremity symptoms and functional impairment among workers employed for 6 months in a new job. Am J Ind Med 2008;51: 932-40.

22. Descatha A, Dale AM, Franzblau A, et al. Natural history and predictors of long-term pain and function among workers with hand symptoms. Arch Phys Med Rehabil 2013;94:1293-9.

23. Roquelaure $\mathrm{Y}, \mathrm{Ha} \mathrm{C}$, Touranchet $\mathrm{A}$, et al. Utilisation du protocole de surveillance en entreprise: expérience du programme de surveillance épidémiologique des TMS dans les Pays de la Loire. Arch Mal Prof Environ 2010;71:420-3.

24. Rempel D, Evanoff B, Amadio PC, et al. Consensus criteria for the classification of carpal tunnel syndrome in epidemiologic studies. $A m$ $J$ Public Health 1998;88:1447-51.

25. Armstrong TN, Dale AM, Al-Lozi MT, et al. Median and ulnar nerve conduction studies at the wrist: criterion validity of the NC-stat automated device. J Occup Environ Med 2008;50: 758-64.

26. Silverstein BA, Fan ZJ, Bonauto DK, et al. The natural course of carpal tunnel syndrome in a working population. Scand $J$ Work Environ Health 2010;36:384-93.

27. Bland JD. Carpal tunnel syndrome. BMJ 2007;335:343-6.

28. Mondelli M, Curti S, Farioli A, et al. Anthropometric measurements as a screening test for carpal tunnel syndrome: receiver operating characteristic curves and accuracy. Arthritis Care Res 2015;67:691-700.

29. Middleton SD, Anakwe RE. Carpal tunnel syndrome. BMJ 2014;349: g6437.

30. Pourmemari MH, Viikari-Juntura E, Shiri R. Smoking and carpal tunnel syndrome: a meta-analysis. Muscle Nerve 2014;49:345-50.

31. Petit A, Ha C, Bodin J, et al. Risk factors for carpal tunnel syndrome related to the work organization: a prospective surveillance study in a large working population. Appl Ergon 2015;47:1-10.

32. Dale AM, Gardner BT, Zeringue A, et al. Self-reported physical work exposures and incident carpal tunnel syndrome. Am J Ind Med 2014;57:1246-54.

33. Carder M, McNamee R, Turner S, et al. Time trends in the incidence of work-related mental ill-health and musculoskeletal disorders in the UK. Occup Environ Med 2013;70:317-24.

34. Bildt C, Alfredsson L, Punnett L, et al. Effects of drop out in a longitudinal study of musculoskeletal disorders. Occup Environ Med 2001:58:194-9.

35. Parot-Schinkel E, Roquelaure $\mathrm{Y}, \mathrm{Ha} \mathrm{C}$, et al. Factors affecting return to work after carpal tunnel syndrome surgery in a large French cohort. Arch Phys Med Rehabil 2011;92:1863-9.

36. Descatha A, Dale AM, Franzblau A, et al. Comparison of research case definitions for carpal tunnel syndrome. Scand $J$ Work Environ Health 2011;37:298-306.

37. Palmer KT, Harris EC, Linaker C, et al. Optimising case definitions of upper limb disorder for aetiological research and prevention: a review. Occup Environ Med 2012;69:71-8.

38. Stock SR, Fernandes R, Delisle A, et al. Reproducibility and validity of workers' self-reports of physical work demands. Scand J Work Environ Health 2005;31:409-37.

39. Leclerc A. Exposure assessment in ergonomic epidemiology: is there something specific to the assessment of biomechanical exposures? Occup Environ Med 2005;62:143-4.

40. ljmker S, Huysmans MA, van der Beek AJ, et al. Software-recorded and self-reported duration of computer use in relation to the onset of severe arm-wrist-hand pain and neck-shoulder pain. Occup Environ Med 2011:68:502-9.

41. Mikkelsen S, Andersen JH. Does self-reported computer work add biologically relevant information beyond that of objectively recorded computer work? Occup Environ Med 2012;69:606.

42. Gerr F, Fethke N. Authors' response. Occup Environ Med 2012;69:525.

43. Cifuentes M, Boyer J, Lombardi DA, et al. Use of O*NET as a job exposure matrix: a literature review. Am J Ind Med 2010;53: 898-914.

44. Atroshi I, Gummesson C, Ornstein E, et al. Carpal tunnel syndrome and keyboard use at work: a population-based study. Arthritis Rheum 2007;56:3620-5.

45. Thomsen JF, Hansson GA, Mikkelsen S, et al. Carpal tunnel syndrome in repetitive work: a follow-up study. Am J Ind Med 2002;42:344-53.

46. Andersen $\mathrm{JH}$, Harhoff $\mathrm{M}$, Grimstrup $\mathrm{S}$, et al. Computer mouse use predicts acute pain but not prolonged or chronic pain in the neck and shoulder. Occup Env Med 2008;65:126-31.

47. Harris-Adamson C, Eisen EA, Kapellusch J, et al. Biomechanical risk factors for carpal tunnel syndrome: a pooled study of 2474 workers. Occup Environ Med 2015;72:33-41. 